\title{
Geographical information system analysis on road accidents involving wandering dogs in the urban area of Naples
}

\author{
Giuseppina Mennonna, ${ }_{1}^{1}$ Carla Murino, ${ }^{1}$ Fabiana Micieli, ${ }^{2}$ Alessandro Costagliola, ${ }^{2}$ \\ Danila D'Angelo, ${ }^{2}$ Orlando Paciello, ${ }^{2}$ Gerardo Fatone, ${ }^{2}$ Francesco Lamagna, ${ }^{2}$ Luigi Navas, ${ }^{2}$ \\ Marina Pompameo, ${ }^{3}$ Leonardo Meomartino ${ }^{1}$
}

\author{
${ }^{1}$ Interdepartmental Centre of Veterinary Radiology, “Federico II" University of Naples; ${ }^{2}$ Department of \\ Veterinary Medicine and Animal Production, "Federico II" University of Naples; ${ }^{3}$ Local Public Health Unit \\ ASL NA1 Veterinary Hospital Presidium, Naples, Italy
}

\begin{abstract}
In this study, the spatial distribution of road accidents involving wandering dogs on urban roads of Naples was assessed using kernel density estimation (KDE). The study included 423 dogs victim of road collisions in the period 2012-2015 collected from the medical records of Interdepartmental Centre of Veterinary Radiology, of Pathological Anatomy Service, of Veterinary Teaching Hospital, "Federico II" University of Naples, and of Veterinary Hospital Attendance of the Local Public Health Unit Napoli1. There were a significant prevalence of young male dogs and the KDE demonstrated the presence of five hotspots in five
\end{abstract}

Correspondence: Leonardo Meomartino, Interdepartmental Centre of Veterinary Radiology, "Federico II" University of Naples, via F. Delpino 1, 80134 Naples, Italy.

Tel.: +39.3356556478 - Fax: +39.0812536021.

E-mail: leonardo.meomartino@unina.it

Key words: Road accidents; Vulnerable user; Dog; Kernel density estimation; GIS; Naples.

Contributions: GM and LM analysed the data and written the paper; $\mathrm{CM}$, FM collected and analysed data; DD'A, OP, GF, FL, LN and MP collected the data and collaborate in reviewing the paper draft.

Conflict of interest: the authors declare no potential conflict of interest.

Funding: this study was supported by the Departmental Research Project Road car accident lesions in small animals of Neapolitan urban area: epidemiological, behavioral and anatomo-pathological characterization to optimize diagnostic and surgical procedures. (Decr. Dir. PG_2015_0056521).

Received for publication: 28 September 2017.

Revision received: 30 August 2018.

Accepted for publication: 9 September 2018.

(C) Copyright G. Mennonna et al., 2018

Licensee PAGEPress, Italy

Geospatial Health 2018; 13:628

doi:10.4081/gh.2018.628

This article is distributed under the terms of the Creative Commons Attribution Noncommercial License (CC BY-NC 4.0) which permits any noncommercial use, distribution, and reproduction in any medium, provided the original author(s) and source are credited. city neighbourhoods. All areas with the highest KDE were found to be peripheral zones in which wide green areas, uncultivated or cultivated, merged with built areas and crossed by large straight roads with a lot of intersections. Wandering dogs as other animals represent a mounting problem on urban roads in Italy, despite of the effort to reduce these populations. Better knowledge of this phenomenon is important with reference to taking countermeasures and improve road safety. It is also important with reference to One Health and the Decade of Action for Road Safety 20112020 of the United Nations.

\section{Introduction}

Since more than 1.25 million people die in traffic accidents each year, they represent the leading cause of human death in the world as reported in 2015 by the World Health Organization (WHO, Global Status Report on Road Safety, 2015). Among the road user categories, bikers, pedestrians and cyclists represent roughly half of the victims and for this reason they are considered as vulnerable users. Just as these categories, stray dogs or owned dogs on the wandering as well as other free-moving animals can be also considered vulnerable road users, even if they are usually not considered as such. While road accidents involving people in Italy tend have recently become significantly lower, road accidents involving wandering animals have increased by $6 \%$ according to the National Institution for Animal Protection (ENPA) (2013). Road accidents involving animals mean not only injuries or death to the animal but also potential injuries to drivers and/or damage to the vehicle.

In the analysis of road safety, in addition to the most accurate statistical data, there is a need to see information geographically. Geographical Information System (GIS) is an important tool for viewing spatial data involving accidents. Apart from statistical data, GIS gives information about the presence of geographical hotspots, which makes it possible to better understand the phenomenon. This type of tool permits merging accident and spatial data, such as geocodes and accident locations. It also helps in calculation of the frequency and rate of accidents (Liang et al., 2005; Erdogan et al., 2008). GIS tools applicable for road accident analysis include census output area estimation, network analysis and kernel density estimation (KDE) (Anderson, 2007; Erdogan et al., 2008; Schuurman et al., 2009). We used KDE to study accidents involving wandering dogs in the urban area of Naples, Italy. The KDE is a non-parametric method used to spatially assess the probability density of a variable and is easy to use and hotspots in large datasets can intuitively be identified providing a statistical and aesthet- 
ically satisfactory outcome (Anderson, 2009). The areas in which the events are more probable have a smoothed feature, since the risk is linked to spatial factors (Silverman, 1986; Anderson, 2009). In order to improve the safety for both animals and drivers, and take the most appropriate countermeasures, better knowledge about road accidents involving wandering animals is needed. The aim of the study was to assess the distribution of road accidents involving wandering dogs in the Neapolitan urban area using GIS tools.

\section{Materials and Methods}

\section{Study area}

The investigation took place in the urban area of Naples, Italy, which has a surface of $117.27 \mathrm{~km}^{2}$ and it is divided in 10 neighbourhoods (Figure 1).

\section{Inclusion data}

From January 2012 to December 2015, on the medical records of the Interdepartmental Centre of Veterinary Radiology, of the Pathological Anatomy Service and of the Veterinary Teaching Hospital of the "Federico II" University of Naples, and of the Veterinary Hospital Attendance of the local Public Health Unit NAPOLI1, data of wandering dogs involved in road accidents in the city of Naples were collected. Both stray dogs and owned dogs free to wonder or lost were considered. Only dogs with a history of known road accidents (owners and/or other witness, police report) and alive at time of recover were included. For each dog, the gender, the age, type of lesion (bone and/or soft tissue), date of admission and the address of the accident or of the recover were recorded. The dogs were grouped into three age classes: young ( $\leq 2$ year), adult ( $>2 \leq 7$ years) and old ( $>7$ years). When no information about the dog was available, the presumptive age was estimated on the basis of clinical, morphologic and radiographic findings. Traumatic lesions were assessed with imaging techniques, surgery or, in case of death after recover, at necropsy.

\section{Statistics used}

Data recorded were analyzed for gender, age classes, and days, months and seasons prevalence with $\chi 2$-test by means of a commercial purposed application (JMPO 8.0.2 SAS Institute Inc. 2009). The level of significance was set at $P<0.05$. For the spatial evaluation, each accident site was georeferenced (longitude and latitude) using Google Heart OpenGL (Google, Mountain view, CA, USA) and its distribution on urban roads assessed trough the $\mathrm{KDE}$ by applying the following formula (Eq. 1):

$$
f(x, y)=\frac{1}{n^{2}} \sum_{i=1}^{n} K\left(\begin{array}{c}
d_{i} \\
h
\end{array}\right)
$$

where $\mathrm{f}(\mathrm{x}, \mathrm{y})$ is the density estimate at the location $(\mathrm{x}, \mathrm{y})$; $\mathrm{n}$ the number of observations, $\mathrm{h}$ the bandwidth or kernel size, $\mathrm{K}$ the kernel function, and $d_{i}$ the distance between location $(x, y)$ and the location of the $i^{\text {th }}$ observation (Anderson, 2009). Since the size of bandwidth have a significant effect on the smoothing of hotspots, i.e. a small bandwidth will produce a discrete patterns while a large bandwidth will generate a smoother surfaces of the derived intensity (Allen and Wong, 2006; Anderson, 2009), the optimal bandwidth was calculated by the following formula (Eq. 2):

$h_{\text {otp }}=\left[\frac{2}{3 n}\right]^{1 / 4} \sigma$

Eq. 2

where $\mathrm{n}$ is the number of observations (road accidents) and the standard distance (Blackburn, 2016). The standard distance was calculated by means of specific tools of the software used to create

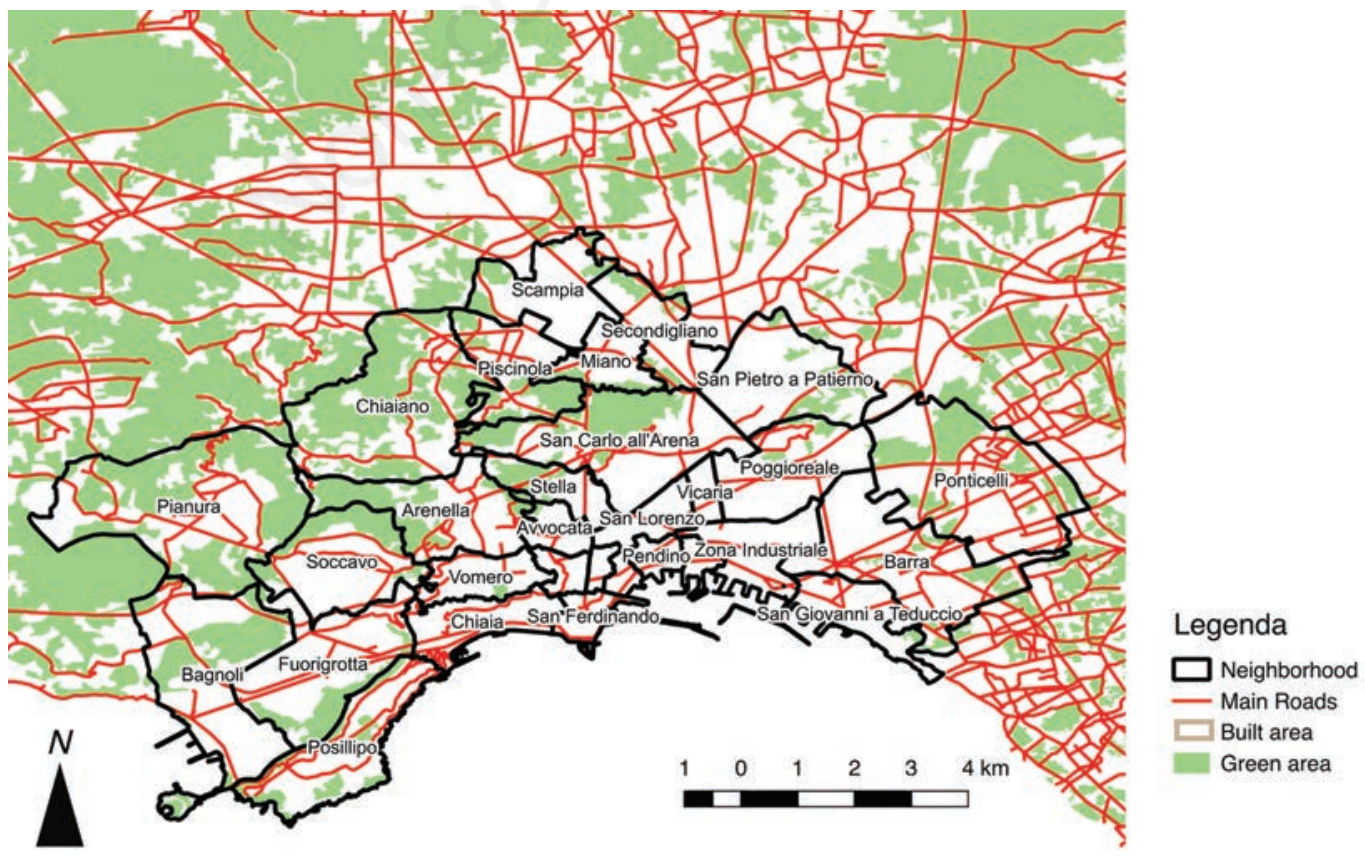

Figure 1. The urban area of Naples with the administrative ten neighbourhoods, the green and the built areas and the main roads. 
the GIS map and to calculate the KDE (QGis ${ }^{\circledR}$ ver. 2.18.2 GNU General Public License, 2017). GIS analysis was performed on shapefile maps downloaded from the institutional site of the Naples municipality (www.comune.napoli.it/flex/cm/pages/ ServerBLOB.php/L/IT/IDPagina/26532).

\section{Results}

During the considered period, 423 dogs involved by road accidents were included. The males (57\%) were significantly more than the females $(43 \%)(\mathrm{P}=0.0041)$. Regarding age, there were 239 young dogs $(56.5 \%), 110$ adults $(26 \%)$ and 74 old ones $(17.5 \%)$ with a significant higher prevalence of the young dogs class $(\mathrm{P}<0.0001)$. There was a higher prevalence of accidents on Mondays but without statistical significance $(\mathrm{P}=0.20)$ (Figure 2). The distribution of accidents showed two peaks on June and January (Figure 3 ) but $\chi 2$ analysis did not demonstrate any significant differences $(\mathrm{P}=0.19)$. Accident occurrence differed between the seasons but without statistical significance $(P=0.14)$ : 104 in the winter $(24.6 \%), 115$ in the spring $(27.2 \%), 117$ in summer $(27.6 \%)$ and 87 in the autumn $(20.6 \%)$. The majority of the lesions affected the skeleton (388 dogs - 81\%), while 94 dogs (19\%) had soft-tissue lesions. After the calculation of the standard distance, the optimal bandwidth for KDE was equal to $0.110 \mathrm{~km}$. Road accidents have taken place throughout the urban area of Naples, but the KDE showed five areas with a higher concentration of road accidents, distributed in five neighbourhoods (Figure 4).

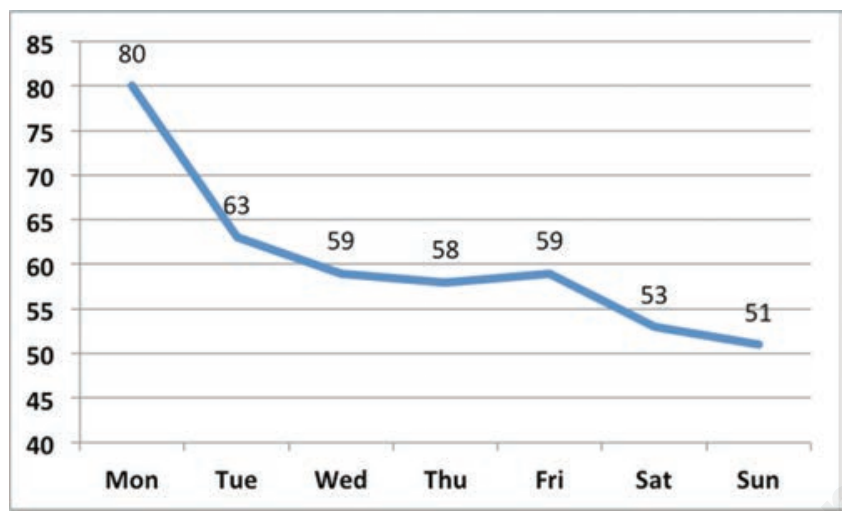

Figure 2. Number of dog recovered in the weekdays. In spite of the higher number of recovers on Monday, no significant differences were found $(P=0.20)$.

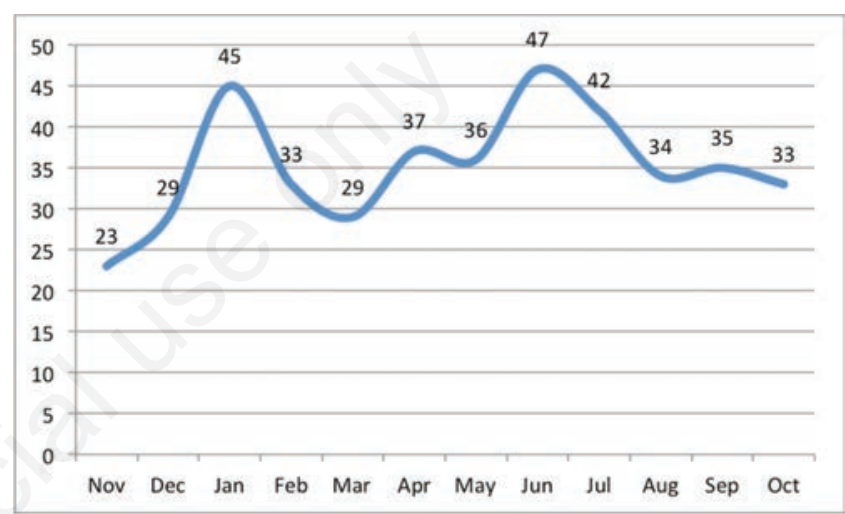

Figure 3. Number of $\mathrm{dog}$ recovered during the months. No significant differences were found $(P=0.19)$ however two peaks, on January and June, are visible.

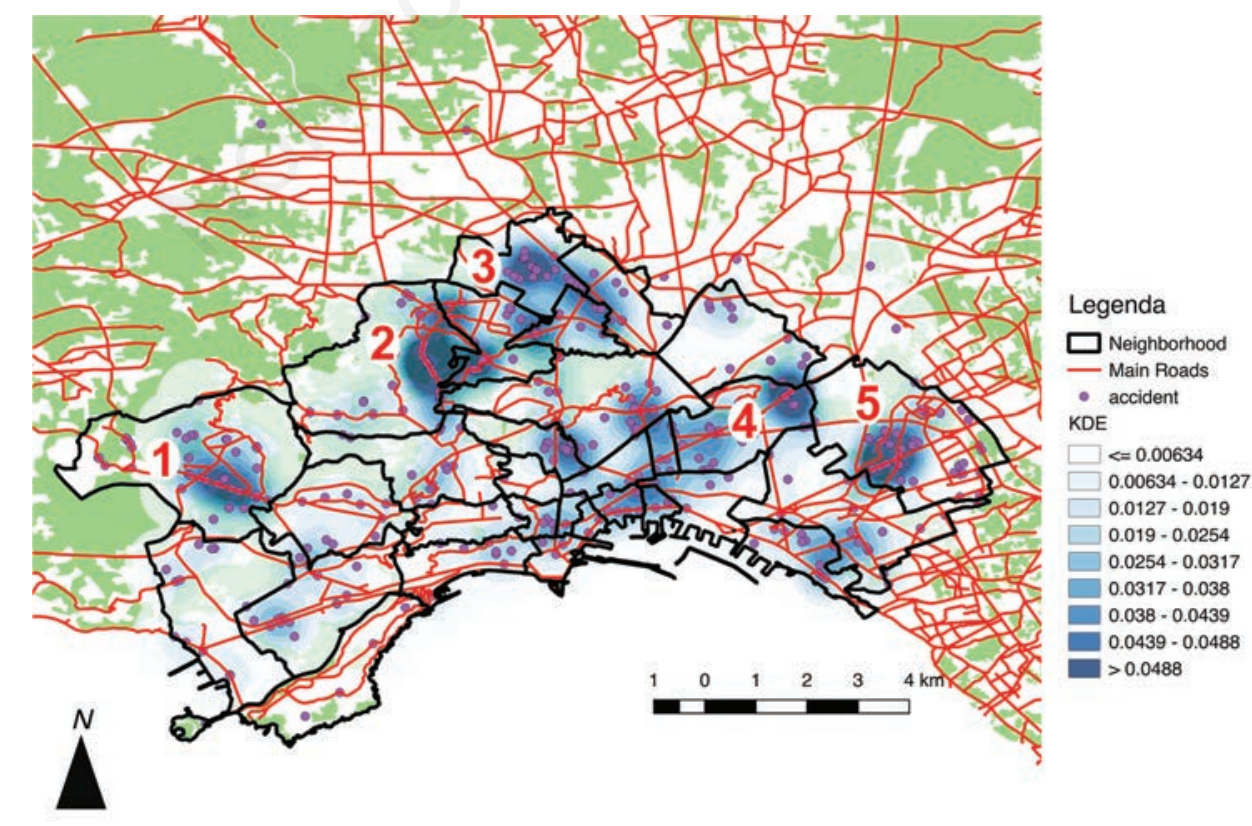

Figure 4. Kernel density estimation (KDE) of road accidents involving wandering dogs on urban area of Naples. There are five hotspots of higher concentrations in five neighbourhoods: 1) Pianura; 2) Chiaiano; 3) Scampia; 4) Poggioreale; 5) Ponticelli. 


\section{Discussion}

Road safety is an important issues for the UN, in fact so important that it has proposed the Decade of Action for Road Safety 2011-2020, an awareness and information campaign promoted by civil society organizations, international agencies, corporations, and Governments in over 100 countries. The aim of the campaign is to increase road safety in order to save 5 million lives in the decade 2011-2020, with particular reference to the protection of the most vulnerable road users. The organization has proclaimed the adoption and enforcement of a law on road safety (Global Plan for the Decade of Action for Road Safety 2011-2020). According to the statistical data from the most of the high-income countries, this campaign is successful in that the incidence of road accidents is decreasing significantly.

However, there was an increasing number of dead or injured companion animals in the richest countries, mainly dogs and cats. Part of the reason is the demographic increase, not only of humans but particularly of dogs where there is a population explosion with a worldwide diffusion into all urban and sub-urban areas of the world (Clutton-Brock, 1995). In Italy, according to the last disposable data, despite efforts to control the canine population, stray dogs counted about 500,000-700,000, particularly in southern regions of the country (Innocenti, 2016). In addition to the stray dogs, an unknown number of owned dogs left free to wander or being lost has to be considered.
The increasing presence of wandering dogs has provided problems for health (zoonotic diseases) and economic (management and costs of kennels) (Fico, 1995). At the same time, the phenomenon of the wandering dogs results in serious problems with regard to road safety demonstrated by the fact that the number of the road accidents caused by wandering animals is increasing, a tendency with is counter to other types of road accidents (ENPA, 2013). The ENPA's data demonstrated (indirectly) that the main clinical reasons for hospitalization of wandering dogs is due a traumatic lesion subsequent to a road accident, as already reported by several studies (Kolata, 1975; Libardoni et al., 2013; Ben Ali, 2013; Bennour et al., 2014; Ballocco et al., 2014; Intarapanich et al., 2016).

Our results on gender and age distribution agree with previous reports (Libardoni et al., 2013; Ballocco et al., 2014). There was a significant higher prevalence of male young dogs. This finding can be related to the ethogram of canine species: in fact, young dogs occupy a low rank until they are three years old after which, during the reproductive period, they tend to increase their home range in order to find a receptive female and therefore they leave the native group. This is also a consequence of the competition with the older males of the same group (Macdonald and Carr, 1995; Pal et al., 1998). This dispersion behaviour of male young dogs, obviously not so skilled to move on the roads in the urban area, predispose them to be victims of road accidents. However, no significant differences were found in the distribution of the accidents among the

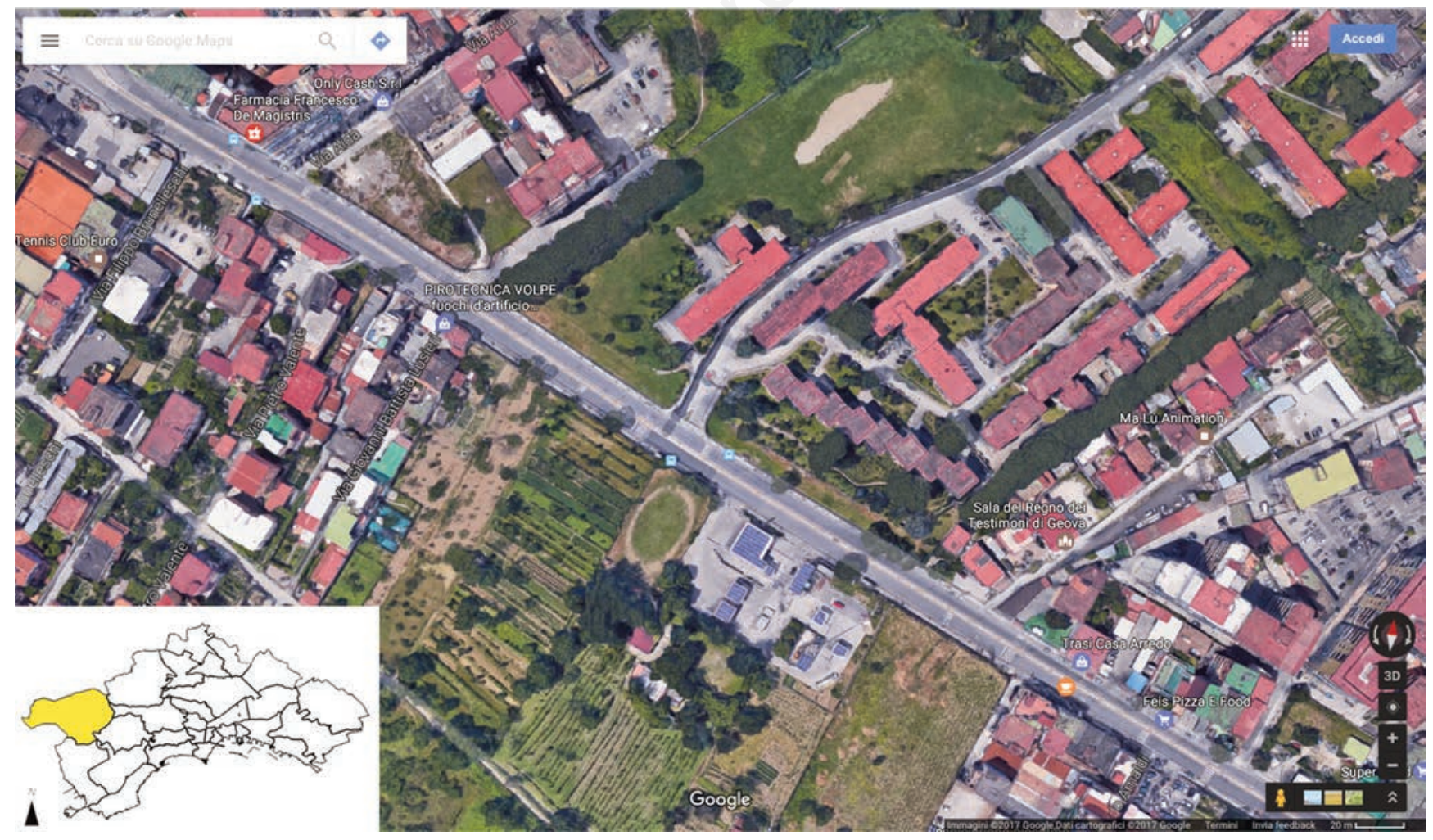

Figure 5. A screenshot from Google Maps ${ }^{\circledR}$ of Montagna Spaccata Street in the neighbourhood of Pianura (neighbourhood highlighted in the box). Many of the common spatial features of the areas involved by hotspots are visible: the main road is straight and it is intersected from a lot of secondary roads; there are many green areas merged with built ones. 
weekdays, the highest number of recovery on Monday could depend on a real higher number of road accidents during the night between Sunday and Monday or on the way work is planned by the four hospital facilities involved in this study. Considering the months, the two peaks of recovery present in June and January is an interesting distribution. Despite the fact that no significant differences were found, that distribution could be related to a particular feature of the oestrus and of the parturitions in our region but, unfortunately, no literature data are available on this topic. To better assess this finding, it would be necessary to increase the number of cases and consider a new campaign to define the population of owned dogs and stray ones.

In our sample, there was a higher prevalence of skeleton lesions compared to soft tissue ones in agreement with previous reports (Ballocco et al., 2014; Intarapanich et al., 2016). However, this result can be affected by the fact that only the living dogs were included. Dogs found dead on the road were directly taken to the incinerator without applying any registration form.

The five neighbourhoods of Naples in which there was higher KDEs have some common spatial features: peripheral zones in which wide green areas, uncultivated or cultivated, merged with built areas and crossed by large straight roads with a lot of intersections (Figure 5). Since the green areas offer many refugees, they are probably ideal to become the home of the stray dogs. Furthermore, those areas have an abundance of food resources deriving from the presence of trash dumpsters along the roads. Another cause may rely to the higher number of dog abandonment, more frequent in these peripheral neighbourhoods. Moreover, the wandering dogs may reach the peripheral neighbourhoods of Naples from the border towns where the sterilization programmes of the Local Public Health Units cannot be applied with the same intensity as in the city area of Naples. Finally, the bad behaviour of many owners, who widely leave their dogs free to wander off in the rural and sub-urban zones of southern Italy, also must be considered.

A number of factors have demonstrated to be involved in facilitate the road accidents: environmental (light conditions, day, night or dawn and twilight), type of road, weather conditions (rain, snow, fog), car speed and driver distraction (Erdogan et al., 2008). The five hotspots with the highest KDEs have many long straight roads with a lot of intersections (Figure 5). On these roads, it is probable that high speed and driver distraction were the main factors resulting in the accidents. Weather factors perhaps are not strictly relevant since no significant differences were present among the seasons and the months. Admittedly, our results are not conclusive about the lightening of the roads during the night hours since the hour of recovery was not recorded, however, it is probable that the night time and the quality of roads lightening are both important risk factors as already reported (Erdogan et al., 2008; Schuurman et al., 2009).

In Italy, only few studies have been carried out in which GIS technology was used to evaluate the road accident risk due to wild animals, particularly deer and wild boars (Banti et al., 2009; Primi et al., 2009). To our knowledge, this study is the first in which GIS was used to evaluate the spatial distribution of road accidents involving wandering dogs in an urban area. The GIS representation of our results easily showed the presence of five hotspots in which the risk of road accidents involving wandering dogs is higher. In those areas, traffic safety must be implemented by precautionary measures and provisions like special road signs, warnings regarding the possible presence of wandering dogs, speed reducers, speed bumps, improved road lightening and increased number of traffic lights (Khan et al., 2004; Erdogan et al., 2008).

\section{Conclusions}

It was demonstrated by application of GIS that in the urban area of Naples there are five hotspots where the risk of road accidents involving wandering dogs is higher. These wandering dogs, as well as other free-moving animals, represent a mounting problem on the urban roads in Italy despite efforts to reduce this kind of population. The knowledge of this phenomenon is crucial in order to increase the safety both for dogs and drivers. It is hoped that in the future accident data regarding free-moving animals will be crossed to those of the Police in the perspective of One Health and of the Decade of Action for Road Safety 2011-2020 of United Nations.

\section{References}

Allen TR, Wong DW, 2006. Exploring GIS, spatial statistics and remote sensing for risk assessment of vector-borne diseases: a West Nile virus example. Int J Risk Assess Manag 6:253-75.

Anderson T, 2007. Comparison of spatial methods for measuring road accident 'hotspots': a case study of London. J Maps 3:5563.

Anderson TK, 2009. Kernel density estimation and K-means clustering to profile road accident hotspots. Acc Anal Prevent 41:359-64.

Ballocco I, Deiana R, Pes A, Visco S, Erriu S, Strina A, Pintore E, Evangelisti MA, Pinna Parpaglia ML, Masala G, Sanna Passino E, Manunta ML, 2014. Le lesioni traumatiche negli animali randagi: analisi retrospettiva. Veterinaria 28:17-22.

Banti P, Nuti S, Ponzetta MP, Sorbetti Guerri F, 2009. Gli incidenti stradali causati dalla fauna selvatica nella Regione Toscana: analisi del fenomeno nel periodo 2001-2008. Ed. Centro Stampa Giunta Regione Toscana.

Ben Ali LM, 2013. Incidence, occurrence, classification and outcome of small animal fractures: a retrospective study (20052010). Int Scholar Sci Res Inn 7:191-6.

Bennour EM, Abushhiwa MA, Ben Ali L, Sawesi OK, Marzok MA, Abuargob OM, Tmumen SK, Abdelhadi JA, Abushima MM, Benothman ME, Said EM, El- Khodery SA, 2014. A retrospective study on appendicular fractures in dogs and cats in Tripoli, Libya. J Vet Adv 4:425-31.

Blackburn JK, 2016. Kernel Density Estimation with Q-GIS. Florida: SEER Lab Univ of Florida Available from: https://www.youtube.com/watch?v=0zirt-3OGbI

Clutton-Brock J, 1995. Origins of the dogs: domestication and early history. In: Serpell J, ed. The domestic dog: its evolution, behaviour and interactions with people. Cambridge, UK: Cambridge University Press. pp 199-216.

National Institution for Animal Protection (ENPA), 2013. Una frenata all'abbandono. National Campaign. Milan, Italy.

Erdogan S, Yilmaz I, Baybura T, Gullu M, 2008. Geographical information systems aided traffic accident analysis system case study: city of Afyonkarahisar. Acc Anal Prevent 40:174-81.

Fico R, 1995. Rapporti di sanità pubblica veterinaria. Studio e gestione di una popolazione canina. Rome, Italy: WHO/FAO, 
Istituto Superiore di Sanità. pp 1-55.

Global Plan for the Decade of Action for Road Safety 2011-2020. Available from: http://www.who.int/roadsafety/decade of action/plan/en/

Innocenti I, 2016. Dossier L.A.V. (Anti Vivisection Legue). Analisi dei dati relativi all'anno 2015, forniti dalle Regioni e Province Autonome italiane, fatta eccezione per Calabria, Emilia Romagna e Sicilia. Available from: http://www.lav.it/news /dossier-randagismo-2016

Intarapanich NP, McCobb EC, Reisman RW, Rozansky EA, Intarapanich PP, 2016. Characterization and comparison of injuries caused by accidental and non-accidental blunt force trauma in dogs and cats. J Forens Sci 61:993-9.

Khan MA, Al Kathairi AS, Garib AM, 2004. A GIS based traffic accident data collection, referencing and analysis framework for Abu Dhabi. Proceedings of CODATU XI World Congress: Towards more attractive urban transportation, 2004 Apr 22-24, Bucarest, Romania. pp 292-302.

Kolata RJ, Johnston DE, 1975. Motor vehicle accidents in urban dogs: a study of 600 cases. J Am Vet Med Assoc 167:939-41.

Liang LY, Mo'soem DM, Hua LT, 2005. Traffic accident application using geographic information system. J East Asia Soc Transport Stud 6:3574-89.
Libardoni RN, Serafini GMC, de Oliveira C, Schimites PI, Chaves RO, Ferante JPS, Costa CAS, do Amaral AS, Raiser AG, Soares AV, 2016. Appendicular fractures of traumatic etiology in dogs: 955 cases (2004-2013). Ciencia Rural 46:542-6.

Macdonald DW, Carr GM, 1995. Variation in dog society: between resource dispersion and social flux. In: Serpell J, ed. The domestic dog: its evolution, behaviour and interactions with people. Cambridge, UK: Cambridge University Press. pp 199216.

Pal SK, Ghosh B, Roy S, 1998. Dispersal behavior of free-ranging dogs (Canis familiaris) in relation to age, sex, season and dispersal distance. Appl Anim Behav Sci 61:123-32.

Primi R, Pelorosso R, Ripa MN, Amici A, 2009. A statistical GISbased analysis of Wild boar (Sus scrofa) traffic collisions in a Mediterranean area. Ital J Anim Sci 8:649-51.

Schuurman N, Cinnamon J, Crooks VA, Hameed SM, 2009. Pedestrian injuries and built environment: an environmental scan of hotspots. BMC Public Health 9:233-42.

Silverman B, 1986. Density estimation for statistics and data analysis. 1st ed. London, UK: Chapman and Hall.

World Health Organization (WHO) Global Status Report On Road Safety, 2015. Geneva, Switzerland: WHO Press. 